\title{
Solution Dosage Form
}

National Cancer Institute

\section{Source}

National Cancer Institute. Solution Dosage Form. NCI Thesaurus. Code C42986.

A clear, homogeneous liquid composed of one or more chemical substances dissolved in a solvent or mixture of mutually miscible solvents. 